\title{
A CLINICAL AGGLUTINOMETER:
}

AN APPARATUS FOR USE AT THE BEDSIDE OR IN THE LABORATORY FOR MAKING RAPID ESTIMATIONS OF

THE AGGIUTININ TITRE OF THE BLOOD.

By R. P. GAR ROW, M.D. ABERD., D.P.H., CAPTAIN, R.A.M.C.

(Report to the Medioal Researeh Committee.)

IN the Arohives of Internal Medicine; Dec 15th, 1910, C. C. Bass and J. A. Watkins describe "A Quick Macroscopic Typhoid Agglutination Test." In carrying out this quick test a drop of 1 in 5 dilution of blood is placed on an ordinary plain microscopic slide along with a drop of a specially dense (about 10,000 millions per c.c.) emulsion of $B$. typhosus. The two drops are mixed together on the surface of the slide, and made to move to and fro by gently rocking the latter for two minutes. A positive result is indicated if the emulsion is broken up into small white masses or clumps visible with the naked eye.

The technique about to be described is simply an elaboration of Bass and Watkins's method with the object of rendering it not merely a qualitative test for agglutinins in the blood, but an accurate quantitative estimation of the agglutinin titre of the blood. This object is attained by means of an apparatus which $I$ have devised and called a " clinical agglutinometer."

The clinical agglutinometer consists of the following parts :-

1. A diluting slab.-A painter's palette made of glazed white porcelain having three rows of seven small cups, and a trough in which the saline solution is contained. (See

Fig. 1.)

2. Diluting pipette.-An ordinary dropping pipette with teat.

3. "Standard"

platinum loop in

handle. The

loop is $3 \mathrm{~mm}$.

diam. and bent

at a right angle

with the stem of

the wire.

4. The agglu-

tinometer slide.-

$\Delta$ piece of ordin

ary clear glass

$25 \mathrm{~cm}$. long, $30 \mathrm{~mm}$. broad, with smooth edges. It is divided by two lines crusswise into three equal parts. (See Figs. 4, 5 , and 6. .)

5. Set of emulsion bottles in stand.-The bacterial emulsions I have used in the agglatinometer are: Bacillus typhosus Eberth, $B$. paratyphosus $A$ Brion-Kayser, $B$. paratuphosus $B$ Schottmüller, $B$. dysenteria Shiga, B. dysenteria Flexner, $B$. dysenterice His, $B$. enteritidis Gaertner, $B$. facalis alkaligines, $B$. coli communis, Vibrio cholerce Koch, Micrococcus melitensis Bruce, M. paramelitensis. The emulsions are made from 24-hour surface agar cultures. The growth is scraped off the surface of the medium in platinum loopfuls and emulsified in $0 \cdot 1$ per cent. formalin in normal saline. The emulsions used for this methol should be dense ones-about 10,000 millions per c.c.

Fig 3.

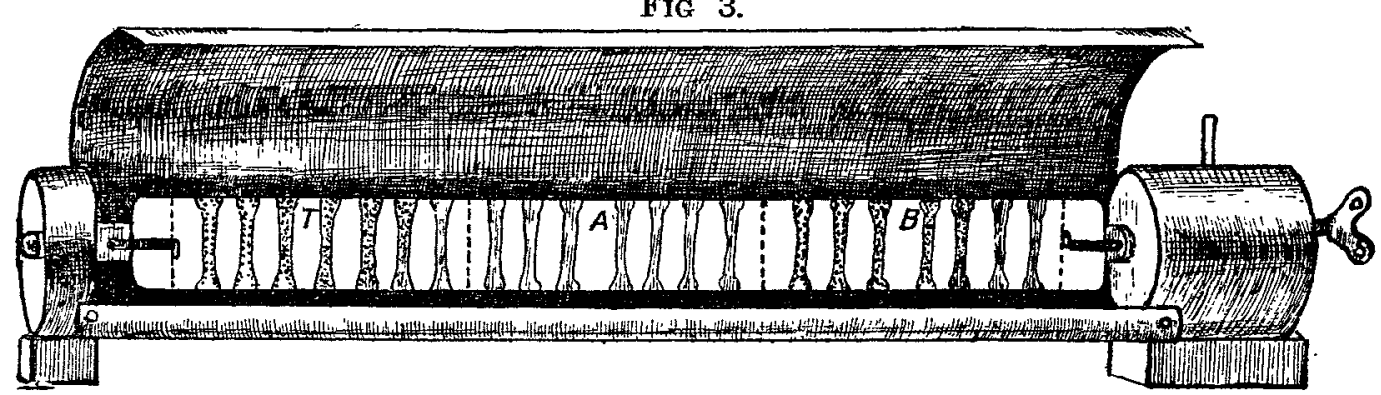

made to revolve on its long axis slowly (about ten revolutions per minute) in an atmosphere saturated with aqueous vapour. The moist chamber is a cylinder of celluloid placed horizontally, the apper half being jointed to form a lid, the lower half lined with filter paper soaked with water. The revolving movement is obtained by means of a simple clockwork attached at one end of the cylinder. It can be stopped at will by means of a lever (after the manner of a Dudgeon's sphygmograph). (See Fig. 3.)

7. A pocket centrifuge. - $A$ small apparatus, not larger than a matchbox and weighing less than two ounces, for centrifuging the blood in Wright's capsules.

Fig. 1.

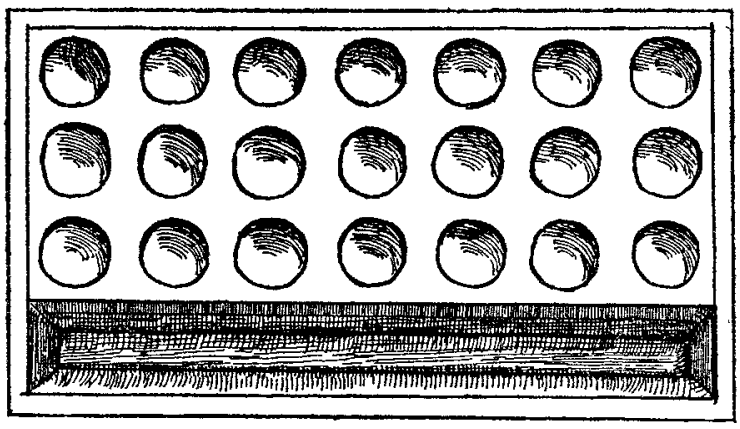

8. Pocket lens. Spirit lamp. Bottle of normal saline. Swabs of cotton-wool. Wright's capsules. Agglutinating sera.

\section{Description of Teohnique in the Use of the Clinicat} Agglutinometer.

1. The diluting process.-(a) The blood for examination is taken from the lobe of the ear in the usual manner into a Wright's capsule, and centrifuged.

(b) By means of a dropping pipette (which during the FIG. 2.

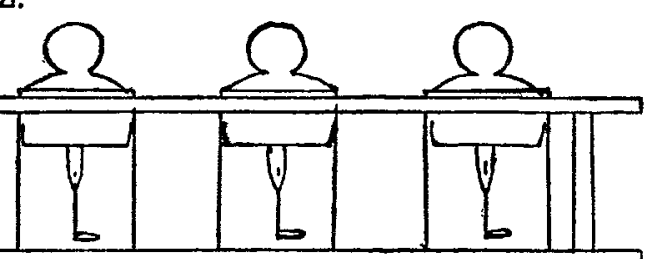
size of the drops) place four drops of ealine into cup No. 1 of the diluting slab and two drops into each of the other cups in the row. (c) To cap No.1 add one drop of the serum to be tested and mix thoroughly by drawing into and expressing from the pipette three times. This forms a 1 in 5 dilution of the patient's serum.

(d) Transfer two drops from the cup No. 1 to cup No. 2, and again mix thorougnly. This forms a 1 in 10 dilution.

(e) Again transfer two drops from cup No. 2 to cup No. 3 , and mix thoroughly. This yields $a 1$ in 20 dilution, and so on to cup No. 7 ( 1 in 320 dilation).

2. The mixing process.-The process of mixing the blood serum and bacterial enulsions is carried out on the surface of the agglutinometer slide. The $25 \mathrm{~cm}$. slide, divided by two lines into three segments, is long enough to take a triplicate series of the seven dilutions, so that the titre for T. $A$ and $B$ emulsions can be found simultaneonsly. Beginning with the highest dilution (1 in 320) loopfuls of the various dilutions of blood serum are deposited in triplicate on the slide which is lying flat on the bench. Opposite each loopful of serum is placed a loopful of bacterial emulsion, as shown in Fig. 4.

Equality in size of loopfuls can only be obtained by holding the handle of the platinum loop vertically throughout the entire process. Beginning with the highest dilution and passing towards the lowest, the loopfuls of serum and emulsion are mixed

The density of all the emulsions should be uniform as far as the eye can judge. Each bacterial emulsion is contained in a small clear glass bottle with wide mouth, having a stopper bearing a "standard" platinum loop bent at a right angle with the stem of the wire. These platinum loops are in all respects the same as the platinum loop in handle. The most gدnerally useful emulsions for diagnostic purposes are Bacillus typhosus, $B$. paratyphosus $A, B$. paratyphosus $B$, and Micrococcus melitensis. (See Fig. 2.)

6. The mechanical mixer.-This consists of a mechanical contrivance, by means of which the agglutinometer slide is across the slide with the edge of the platinum loop. When this is complete there are on the surface, mixtures of bacterial emulsions of T., and A and B with blood serum in the following titres: $1 / 10,1 / 20,1 / 40,1 / 80,1 / 160,1 / 320,1 / 640$. (Fig. 5.)

The slide so loaded is placed carefully in the moist chamber of the mechanical mixer where it is received and held fast by a clip at each end. The clockwork is started by means of the lever, and the slide allowed to revolve slowly for five minutes, during which time tbe mixtures run to and fro across the slide. The bulk of fluid is not enough to allow 
the mixtures to run off the slide at the edges, nor for the various dilutions to run into one another.

At the end of five minutes the agglutinometer slide is removed and examined by the naked eye (aided, if necessary, by a pocket lens) in a good light against a black background. Agslutination converts the mixtures from homogeneous milky emulsions into a condition in which the agglutinated masses of bacilli float about like minute white flakes in a clear fluid. In a strongly agglutinating blood this takes place in the lower dilutions almost instantaneously after the agglutinometer slide begins to revolve. The change is very striking and can be easily seen with the naked eye. In the higher dilutions the change may take three or four minutes and be observable only with the aid of a pocket lens. If no change is visible with the pocket lens in the 1 in 10 dilution at the end of five minutes' time limit no agglutination of any diagnostic significance is present in the blood.

The diagram, Fig. 6, represents the appearance of the agglutinates $T$. up to 1 in 320 and $B$ ap to 1 in 160, the $A$ emulsion being negative. agglutinometer slide in the case of a patient whose blood

and agglutinarle substances are constantly being brought into contact with one another and their union facilitated. The same constant movement of a staining solution over a section of tissue or a blood film hastens the staining process and renders it more complete. For the same reason photographers use a mechanical rocker which causes the developing solution to move constantly to and fro over the photographic plate. The physical change-the aggregation of the bacilli into clumps - is also greatly accelerated by rolling the bacilli on one another. In the lower dilutions in which agglutinin is concentrated, agglutination appears instantaneously throughout the emulsions, but in the higher dilutions, in which agglutinin has been reduced to a mere trace, the clumps will be seen to form slowly along two lines which correspond to the junction of the quickly moving central stream and slowly moving peripheral stream on either side-that is to say, the position in which the rolling action on the bacilli is most marked. They tend to pass outwards into the peripheral stream and finally settle along the edge of the fluid.

The Uses and Advantages of the Clinioal Agglutinometer.

Simplioity.-The technique is simple and easy. Little is left to the manipulative dexterity of the operator, and thus satisfactory results should be obtained by men with little experience of the method.

Speed.-The method is extremely rapid. After a little practice, specimens of blood can be examined and the results recorded at the rate of 10 per hour-an all-important consideration in war-time.

Acouracy. - The titre found by the agglntinometer in 5 minutes is the same on an average to within one dilution, as that obtained by the elaborate method in tubes in 2-24 hours. The end-point is as sharp as that in tubes and easily read after a little practice. The method is therefore capable of detecting with all sufficient accuracy th ise fluctuations in titre which take place during the course of enterica. The special sphere of usefulness of the clinical agglutinometer is in the making repeated examinations in those cases of clinical enterica after triple inoculation in which attempts at isolation of the bacillus from the blood, urine, and fæces have failed.

(Note.-It is absolutely essential that the examination of the slide be out in a good light again - $t$ a black background some distance away (say 3 or 4 feet), otherwise it is difficult or impossible to read the results.)

In examining the bloods of patients suffering from typhoid and paratyphoid infection it will frequently happen that all the dilutions up to 1 in 640 show agglutination. In such a case a further series of higher dilutions in the same geometrical progression is made, thus :-

(a) Into each of the cups in the second row on the diluting slab drop two drops of normal saline.

(b) Transfer two drops from the 1 in 320 dilution to cup No. 1 of the second row and mix thoroughly-this makes 1 in 640 dilution.

(c) Transfer two drops of 1 in 640 dilution into cup No. 2 of the second row and mix thoroughly, and so on to as high a dilution as it is considered necessary to reach the agglutinin titre of the blood. Now clean the agglutinometer slide with a cotton-wool swab wet with 5 per cent. carbolic, dry it, and flame it. Distribute the higher series of dilutions in platinum loopfuls on the slide in precisely the same way as for the lower series of dilutions, place opposite each dilution a loopful of emulsion, mix the two together across the slide, and place the slide in the mechanical mixer as before. The agglntinin titre of the blood is the highest dilution in which definite flakes of agglutinated bacilli can be seen with the aid of a pocket lens. It is, of course, essential that the dilution beyond this (the ultimate dilution) be absolutely negative. This indicates the penultimate dilution as the limit of the agglutinin titre of the blood and acts as a control for each test.

$$
\text { Theory of Aotion of the Agglutinometer. }
$$

For the purpose of explaining the action of the agglutinometer the phenomenon of agglutination may be considered to consist of two processes:-

1. The union of agglutinin with the agglutinable substance (whether this is in the nature of a true chemical union or is merely " adsorption" is here immaterial).

2. The aggregation of the bacilli into clumps. Both these processes are greatly accelerated by the movement to and fro to which the mixtures of serum and emulsions are subjected in the meohanical mixer. Different portions of agglutinin
Fvidence is accumulating that in these cases this special method of examination gives valuable help in diagnosis at a small cost in time, trouble, and material.

The diagrams illustrating this article were kindly drawn for me by Captain Philip H. Bahr, R.A M.C. This agglutinometer may be obtained through Dr. Thos. G. Nicholson, resident medical officer at the London Fever Hospital, Liverpool-road, Islington, London, $\mathrm{N}$.

\section{A SHORT NOTE ON}

\section{THE EFFECT OF PYREXIA ON INOCULA- TION AGGLUTININS.}

\section{By G. SELBY WILSON. M. B., B.S. LoND., M.R.O.S. L R.O.P. LOND.}

TEMPORARY LIEUTENANT, R.A.M.O.

(From the Bactoriological Laboratory, Charing Cross Hospital.)

IN consideration of the large number of results which have been published by Dreyer, Inman, and Ainley Walker, working by the macroscopic method on the one hand, and Tidy, working by the microscopic method on the other hand, in regard to the effect of pyrexia on the agglutinin content of the blood of those persons who have been previonsly inocnlated with typhoid vaccine, and in view of the discordancy which has occurred in the conclusions which have been drawn from these two methods, it was suggested that it would be interesting to examine the serum of each individual patient by both the macroscopic and microscopic procedures. For this purpose a series of 97 soldiers and others, who had been inoculated within the preceding 20 months against typhoid fever, was taken, and the agglutinin titre of the 